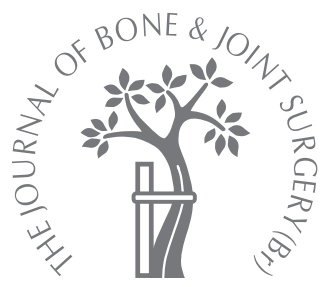

- CASE REPORT

\title{
Slipped upper femoral epiphysis in Hashimoto's thyroiditis in a 29-year-old man
}

\author{
A. T. Oommen, \\ V. Madhuri, \\ T. V. Paul \\ From Christian \\ Medical College, \\ Vellore, Tamil Nadu, \\ India
}

A. T. Oommen, MS(Ortho), DNB(Orth), Assistant Professor In V. Madhuri, MS(Ortho), $\mathrm{MCh}$ (Ortho), Professor and Head

Department of Orthopaedics T. V. Paul, MDMed,

DNB(Endocrinology), Assistant Professor

Department of Endocrinology Christian Medical College and Hospital, Vellore 632004, Tamil Nadu, India.

Correspondence should be sent to $\operatorname{Dr}$ A. T. Oommen; e-mail: lillyanil@cmcvellore.ac.in

(c)2009 British Editorial Society of Bone and Joint Surgery doi:10.1302/0301-620X.91B5. $22160 \$ 2.00$

$J$ Bone Joint Surg [Br] 2009;91-B:666-8.

Received 5 December 2008 Accepted 16 January 2009

\begin{abstract}
Slipped upper femoral epiphysis (SUFE) with an open physis is rare in an adult and the condition may present without prior diagnosis of an underlying medical condition. We have treated a 29-year-old man with bilateral SUFE associated with autoimmune hypothyroidism. The management was delayed and complicated by co-existing autoimmune chronic active hepatitis. He underwent thyroxine therapy and bilateral pinning in situ with a single ASNIS screw. Closure of the physis occurred after five months on the right side. The left side required a further corrective intertrochanteric osteotomy, and it was only after 13 months that complete fusion of this physis was seen. The case highlights the need to consider endocrine and metabolic conditions in atypical presentation of SUFE.
\end{abstract}

Slipped upper femoral epiphysis (SUFE) is caused by mechanical insufficiency of an abnormally weak proximal femoral physis or by abnormal loading of a normal physis., ${ }^{1,2}$ Conditions that weaken the physis include endocrine abnormalities, systemic diseases such as renal osteodystrophy, and radiation therapy. ${ }^{1}$ Abnormal loading is a result of mechanical factors, including obesity and anatomical variation in the proximal femur and acetabulum. ${ }^{1}$ Patients with endocrinopathies have an estimated sixfold increase in the incidence of SUFE and represent $5 \%$ to $8 \%$ of patients with the condition. Other factors, such as race, gender, season and geographical location, also contribute to the aetiology. ${ }^{2}$

SUFE is overwhelmingly a disease of adolescents and is not usually encountered in adults. In hypothyroidism, there is a delay in development of the epiphysis and its appearance may be similar to that in Perthes' disease. Untreated hypothyroidism is associated with open growth plates beyond the normal age for closure. However, SUFE has been reported only a few times in the adult with hypothyroidism. ${ }^{3}$ We present the case of a 29-year-old man with bilateral SUFE. Autoimmune Hashimoto's thyroiditis was diagnosed during the investigation of this unusual case.

\section{Case report}

A 29-year-old man presented in November 2005 with a ten-year history of bilateral hip pain. This had increased during the preceding two years and he had been bedridden because of pain and inability to bear weight for the previous five months. He had consulted a hepatologist for jaundice and abdominal distension three months before his visit to us and, after a biopsy and liver function tests, had been diagnosed as having chronic liver disease secondary to autoimmune hepatitis. His past history suggested normal physical and mental development in early childhood.

On examination he was of moderate build and could not stand independently. Both hips had external rotation deformities of $45^{\circ}$ on the left and $30^{\circ}$ on the right. Flexion was to $100^{\circ}$ and abduction to $10^{\circ}$ in both hips. All movements were associated with significant pain and spasm. Radiographs revealed bilateral SUFE (Fig. 1). A technetium bone scan showed increased uptake in both hips but no abnormalities elsewhere. A diagnosis of chronic SUFE was made. This condition in a 29 -yearold suggested a significant metabolic or endocrine abnormality. On detailed examination, his weight was $68 \mathrm{~kg}$, height $163 \mathrm{~cm}$ and arm span $173 \mathrm{~cm}$. His upper segment measured $77 \mathrm{~cm}$, the lower segment $86 \mathrm{~cm}$, and the body mass index was $25.59 \mathrm{~kg} / \mathrm{m}^{2}$, the upper limit of normal. He had abdominal distension with hepatomegaly, prominent veins on the anterior abdominal wall and gynaecomastia. The scrotal sacs were poorly developed and his testes measured about $6 \mathrm{ml}$ with a Prader's orchidometer, compared with the normal $15 \mathrm{ml}^{4}$ There were no secondary sexual changes, such as facial, axillary and pubic hair. Haematological investigations showed an elevated 


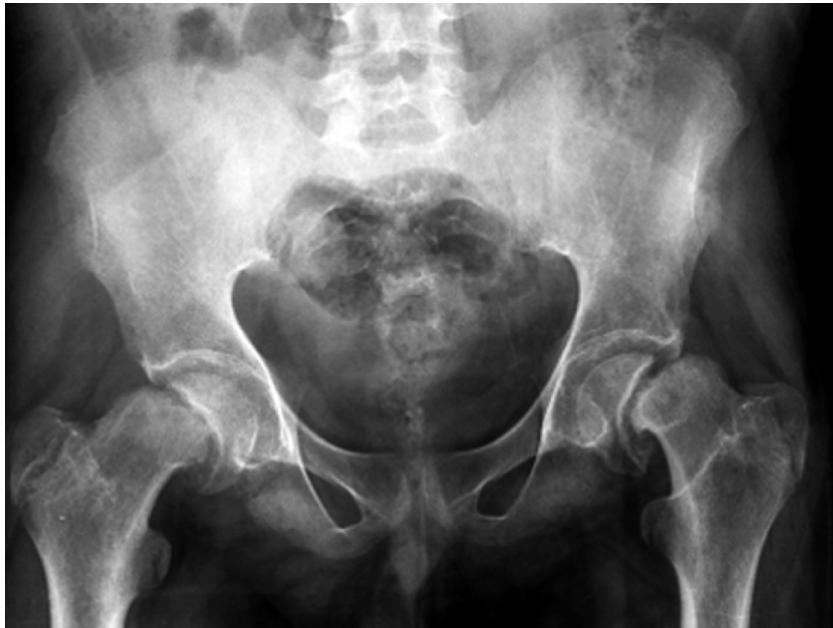

Fig. 1

Pre-operative radiograph showing bilateral severe slipped upper femoral epiphysis.

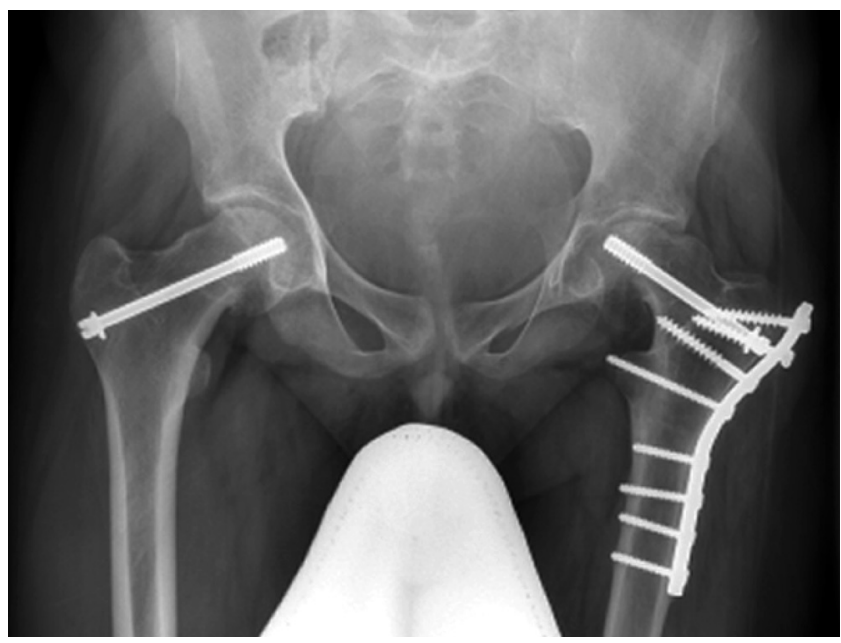

Fig. 2

Follow-up radiograph after bilateral in situ pinning and valgus intertrochanteric osteotomy on the left side, showing fused epiphyses bilaterally.

thryoid-stimulating hormone at $32.7 \mu \mathrm{IU} / \mathrm{ml}$ (normal 0.3 to 4.5). The thyroxine $\left(\mathrm{T}_{4}\right)$ level was reduced at $2.43 \mu \mathrm{g} \%$ (normal 4.5 to 12.5 ). There was significant elevation of the antithyroglobulin and antimicrosomal thyroid antibodies. The total proteins were $9.4 \mathrm{~g} \%$. The serum globulin was $4.5 \mathrm{~g} \%$ with a reversed albumin:globulin ratio. The liver biopsy showed a mixed macronodular and micronodular cirrhosis with moderate activity.

A diagnosis of Hashimoto's autoimmune thyroiditis with hypothyroidism, hypogonadotrophic hypogonadism and autoimmune liver disease was made. He was started on an immuno-suppressant (azathioprine), thyroxine, propanolol to prevent portal hypertension, and a diuretic (frusemide).
Bilateral pinning in situ using a single cannulated hip screw (ASNIS; Stryker Howmedica, Newbury, United Kingdom) was carried out under general anaesthesia in May 2006. He was immobilised in a hip spica for three months after removal of the sutures. The right physis had closed five months after pinning, and the residual deformity on the left was corrected by a subtrochanteric valgus derotation osteotomy in January 2007. This physis had closed five months later, in June 2007. When last seen in September 2008, he could walk unaided. Both hips had flexion to $110^{\circ}$, abduction to $40^{\circ}$ and adduction to $30^{\circ}$. The left side had external rotation to $90^{\circ}$ and internal rotation to $20^{\circ}$. The right hip had an external rotation deformity of $20^{\circ}$ with a further $70^{\circ}$ external rotation. Radiographs showed fusion of both physes (Fig. 2).

\section{Discussion}

SUFE at an unusual age is associated with endocrine abnormalities such as hypothyroidism, panhypopituitarism, hypogonadism, abnormalities of growth hormones, hyperparathyroidism and hypoparathyroidism. ${ }^{1}$ In Down's syndrome, SUFE may occur because of the increased incidence of hypothyroidism and hypogonadism. Growth hormone therapy can result in SUFE and in patients with renal osteodystrophy, the management of associated hyperparathyroidism reduces the risk and progression of SUFE. ${ }^{1}$

The presence of immune complexes in the synovial fluid of hips with SUFE has suggested an immune-mediated aetiology ${ }^{1}$ and the unusual feature in our case is the open physis due to autoimmune hypothyroidism following normal development in early childhood.

The growth and maturation of cartilage and its subsequent calcification require normal levels of growth and thyroid hormones. In hypothyroidism, there is an abnormal increase in the degeneration of chondrocytes, enhanced mineralisation of matrix and inhibition of ossification. ${ }^{5}$ The epiphysiometaphyseal junction in an untreated case is a lattice of solidly calcified cartilaginous matrix, ${ }^{5}$ and the physis distal to this becomes more vulnerable to shearing.

The incidence of SUFE in India is unknown, but from our experience in a tertiary referral centre we do not see the condition more than once a year. Therefore, in our population, any case should be assumed to have an underlying pathology and investigated accordingly. In spite of hormone therapy and pinning in situ, our patient showed no evidence of fusion of the growth plate until five months after operation on the right side and a further eight months on the left. Others have reported one year for fusion of the growth plate with medical management alone. ${ }^{6}$

No benefits in any form have been received or will be received from a commercial party related directly or indirectly to the subject of this article. 


\section{References}

1. Lovell WW, Winter RB, Morrissey RT, Weinstein SL, eds. Lovell and Winter's paediatrics orthopaedics. Sixth edition. Philadelphia: Lippincott Williams and Wilkins, 2006:1086-8.

2. Murray AW, Wilson NI. Changing incidence of slipped capital femoral epiphysis: a relationship with obesity? J Bone Joint Surg [Br] 2008;90-B:92-4.

3. Puri R, Smith CS, Malhotra D, et al. Slipper upper femoral epiphysis and primary juvenile hypothyroidism. J Bone Joint Surg [Br] 1985;67-B:14-20
4. Styne DM, Grumbach MM. Puberty: ontogeny, neuroendocrinology, physiology and disorders. In: Kronenberg HM, Melmed S, Polonsky KS, Larsen PR, eds. Williams textbook of endocrinology. 11th edition. Saunders: Elsevier, 2008:969-79.

5. Burrow SR, Alman B, Wright JG. Short stature as a screening test for endocrinopathy in slipped capital femoral epiphysis. J Bone Joint Surg [Br] 2001;83-B:263-8.

6. Nourbakhsh A, Ahmed HA, McAuliffe TB, Garges KJ. Bilateral slipped capital femoral epiphysis and hormone replacement. Clin Orthop 2008;466:743-8. 